\title{
BMJ Global Health Building HIV healthcare worker capacity through telehealth in Vietnam
}

Todd M Pollack (D) , ${ }^{1,2}$ Vo Thi Tuyet Nhung, ${ }^{3}$ Dang Thi Nhat Vinh, ${ }^{3}$ Duong Thi Hao, ${ }^{3}$ Le Thi Thu Trang, ${ }^{1}$ Pham Anh Duc, ${ }^{1}$ Nguyen Van Kinh, ${ }^{4}$ Nguyen Thi Hoai Dung, ${ }^{4}$ Duong Lan Dung, ${ }^{5}$ Nguyen Thi Ninh, ${ }^{6}$ Ho Thi Thanh Huyen, ${ }^{7}$ Vo Xuan Huy, ${ }^{8}$ Duong Minh Hai, ${ }^{9}$ Truong Huu Khanh, ${ }^{10}$ Nguyen Thi Thu Hien, ${ }^{11}$ Pham Tram An Khuong, ${ }^{12}$ Nguyen The Trong, ${ }^{13}$ Nguyen Van Lam, ${ }^{14}$ Vu Ngoc Phinh, ${ }^{1}$ Do Thi Phuong, ${ }^{1}$ Nguyen Duc Duat, ${ }^{1}$ Nguyen Thanh Liem, ${ }^{3}$ Nguyen Thanh Binh, ${ }^{1}$ Nguyen K Chi, ${ }^{15}$ Le Ngoc Yen, ${ }^{16}$ Lisa Cosimi ${ }^{2}$
To cite: Pollack TM, Nhung VTT, Vinh DTN, et al. Building HIV healthcare worker capacity through telehealth in Vietnam. BMJ Global Health 2020;5:e002166. doi:10.1136/ bmjgh-2019-002166

Handling editor Soumitra S Bhuyan

Received 14 November 2019 Revised 12 March 2020 Accepted 15 March 2020

\section{Check for updates}

\section{Author(s) (or their} employer(s)) 2020. Re-use permitted under CC BY-NC. No commercial re-use. See rights and permissions. Published by BMJ.

For numbered affiliations see end of article.

Correspondence to Dr Todd M Pollack; tpollack@bidmc.harvard.edu

\section{ABSTRACT}

Development of a robust technical assistance system is an essential component of a sustainable HIV response. Vietnam's National HIV Program is transitioning from a largely donor-funded programme to one primarily supported by domestic resources. Telehealth interventions are increasingly being used for training, mentoring and expert consultation in high-resource settings and hold significant potential for use as a tool to build HIV health worker capacity in low and middle-income countries. We designed, implemented and scaled up a novel HIV telehealth programme for Vietnam, with the goal of building a sustainable training model to support the country's HIV workforce needs. Over a 4-year period, HIV telehealth programmes were initiated in 17 public institutions with participation of nearly 700 clinical sites across 62 of the 63 provinces in the country. The telehealth programme was used to deliver certificate training courses, provide clinical mentoring and case-based learning, support programme implementation, provide coaching in quality improvement and disseminate new guidelines and policies. Programme evaluation demonstrated improved health worker selfreported competence in HIV care and treatment and high satisfaction among the programme participants. Lessons learnt from Vietnam's experience with telehealth can inform country programmes looking to develop a sustainable approach to HIV technical assistance and health worker capacity building.

\section{INTRODUCTION}

Vietnam's National HIV response has been largely supported by donor funding, including the US President's Emergency Plan for AIDS Relief (PEPFAR) and the Global Fund for AIDS, Tuberculosis and Malaria since 2003. During this time, Vietnam has rapidly scaled up antiretroviral therapy (ART) from fewer than 1000 patients on ART in 2006 to more than 130000 in 2018. ${ }^{1}$ The country's HIV treatment programme has achieved remarkable success. More than $93 \%$ of patients on

\section{Summary box}

Health worker training and mentoring has been an integral component of the scale-up of antiretrovira therapy around the world

- Scalable and sustainable models of health worker capacity building are needed to support national HIV programmes in low and middle-income countries.

- Telehealth is a novel approach that uses live online videoconferencing technology to connect remote health workers with experts from specialty centres for the purpose of training, mentoring and support of programme implementation.

- Lessons learnt from Vietnam's experience can provide national programmes and training institutions with approaches to designing, implementing and sustaining HIV telehealth programmes in their settings.

ART who had a viral load test in 2019 achieved viral suppression to less than 200 copies $/ \mathrm{mL}$. ${ }^{1}$ Vietnam was the first country in Asia to adopt a target of $90 \%$ diagnosed, $90 \%$ treated and $90 \%$ virally suppressed (90-90-90) by $2020{ }^{2}$

In Vietnam, HIV treatment is delivered through a decentralised network of more than 400 clinical sites across 63 provinces. ${ }^{3}$ As in other settings, training and on-site mentoring of clinic health workers has been a critical factor in the success of ART scale-up efforts. ${ }^{4-8}$ This support has largely been delivered through collaborations between international organisations and national training institutions. However, the HIV response in Vietnam, as in many countries, is in a period of transition from a donor-supported programme to one supported and financed by national institutions. ${ }^{9}$ This shift has been accompanied by alterations in health service delivery models, new policies and guidelines, increased rate of staff turnover and updated 
requirements for certification to prescribe antiretrovirals. In this context, access to continuing medical education (CME), clinical training and mentoring, and expert consultation are significant challenges facing health workers in the national HIV programme. Moving from a donor-supported technical assistance (TA) system to a one led by national institutions is an essential step towards a sustainable HIV response. ${ }^{10}$

In Vietnam, the higher level facilities of the healthcare system are mandated to provide training and technical support to the lower level (ie, provincial, district and commune). The country is divided into regions with specialty hospitals responsible for a particular catchment area. The National Hospital for Tropical Diseases and the Hospital for Tropical Diseases in Ho Chi Minh City (HCMC) provide training and mentoring in the north and south, respectively; the Vietnam National Children's Hospital and the Children's Hospital No 1 provide training in paediatric HIV care. Healthcare workers receive training on HIV prevention, care and treatment through in-service short courses organised by the Ministry of Health $(\mathrm{MOH})$, these specialty hospitals and international non-governmental organisations. With expertise and capacity concentrated primarily in a few centres, trainees must travel frequently to the national or regional level for training. Following training, on-site clinical mentoring and consultations may be provided; primarily in high-burden districts and provinces. However, this system has many limitations, including the need for frequent travel by both trainees and trainers resulting in significant time away from patient care, difficulty in reaching health workers in remote regions of the country, inappropriate participant selection leading to mismatch between training content and participant needs, and high cost. To overcome these challenges and to address the need for a more sustainable approach to HIV health workforce development, we developed and expanded a telehealth programme whereby specialty centres provide training and ongoing mentoring to HIV providers in their region.

Increasingly, telehealth interventions are being used to provide training, mentoring and expert consultation in HIV and other diseases. ${ }^{11-14}$ Project Extension for Community Healthcare Outcomes (ECHO), a system of telementoring

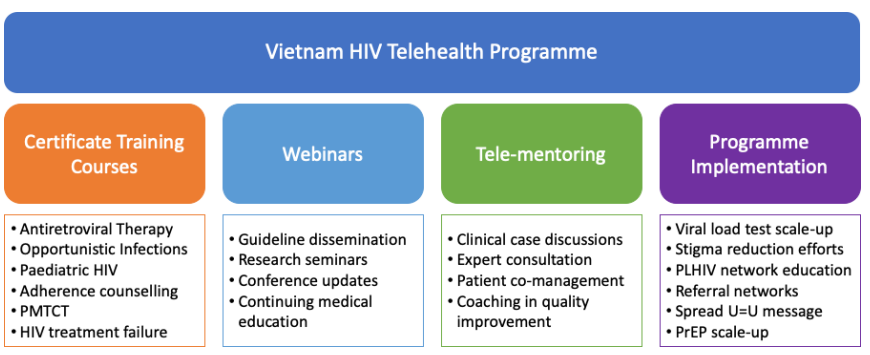

Figure 1 Overview of the Vietnam HIV telehealth programme. PMTCT, prevention of mother-to-child transmission; PrEP, pre-exposure prophylaxis; PLHIV, People Living with $\mathrm{HIV} ; \mathrm{U}=\mathrm{U}$, undetectable=untransmittable. developed by the University of New Mexico, uses videoconferencing technology to connect community-based physicians with specialists from academic medical centres for training and patient comanagement. ${ }^{15}$ The ECHO model focuses on case-based learning, adherence to best practices and monitoring outcomes. ${ }^{15}$ It has been shown to improve access to treatment of chronic hepatitis $\mathrm{C}$ virus infection, ${ }^{16}$ and has been adapted for training health professionals in a variety of chronic diseases. ${ }^{13}$ 17-22 Similar to ECHO, the Vietnam HIV telehealth programme aims to build health worker capacity through didactic training, case-based and peer-to-peer learning, and distance mentoring from HIV experts; and to increase access to up-to-date knowledge for health workers in remote and rural areas. In this paper, we describe the development and scale-up of HIV telehealth in Vietnam including the successes, challenges and lessons learnt.

\section{PROGRAMME DEVELOPMENT AND SCALE-UP}

Beginning in 2014, telehealth networks were established, using a hub and spoke model, with national, regional and provincial institutions serving as central hubs to support provincial and district HIV providers. Hubs were selected based on their recognised role as training institutions in the healthcare system. We developed a guideline for implementation, including standard operating procedures, checklists and templates for session presentations. We conducted a baseline needs assessment, provided hubs and participating clinics with necessary equipment and trained our national and regional partners to use Zoom videoconferencing software (Zoom Video Communications, V.4.4.6) to implement telehealth sessions. Participants from the provincial, district and community levels joined sessions via clinic or personal computers, tablets and mobile phones.

The Vietnam HIV telehealth programme was launched in June 2014 at the University of Medicine and Pharmacy in HCMC with participation of HIV care sites in 10 provinces. Building on experience from the initial pilot, we supported additional partner institutions to initiate programmes through trainings and experience-sharing workshops. We used an 'adapt to adopt' approach when scaling up the programme where hubs were encouraged to design their own programmes for implementation. ${ }^{23}$ As a result, a variety of session types were organised depending on the need and the preference of each hub. These included webinars, case-based learning, programme implementation network meetings, clinical mentoring, coaching in quality improvement and certificate training courses (figure 1). The monthly programme schedule of each hub was made available on a programme website and via email to registered participants. The various session types are further described below.

\section{Online certificate training}

Physicians in Vietnam are required to have certification in HIV treatment prior to prescribing ART. Once the 

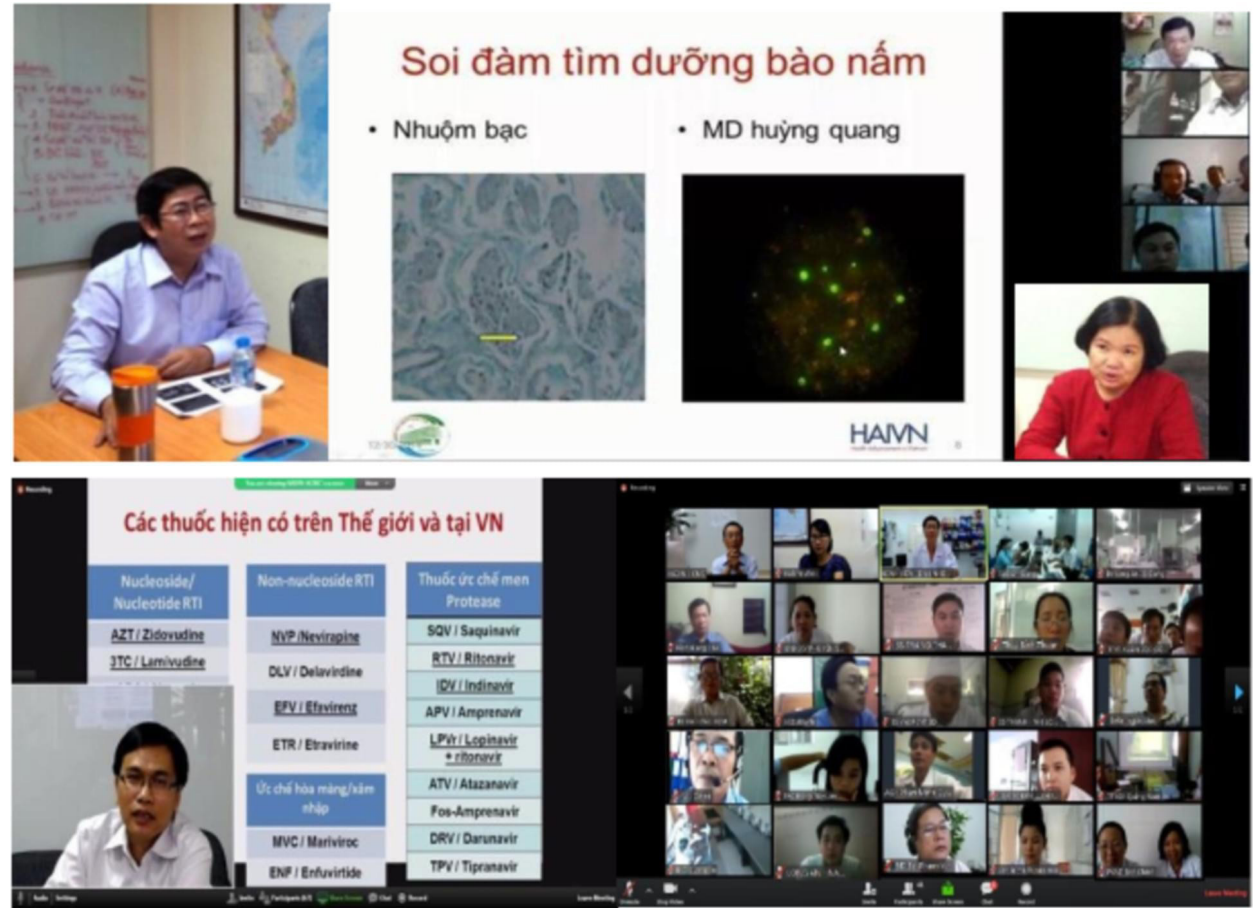

Figure 2 Screenshot of online training in HIV care and treatment.

telehealth networks were established, in-person didactic trainings were replaced by online courses delivered via live videoconferencing using curricula approved by the Vietnam MOH. Participants were required to join individually, with a webcam if available, to assist with attendance taking and to enhance interactivity of the training (figure 2). A typical course occurred over two afternoons per week for 4-5 weeks. Registered participants received an email with the detailed schedule and instructions on how to access the course. Those who attended at least $70 \%$ of sessions and passed the test at the end of the course $(\geq 70 \%$ correct answers) were awarded a certificate.

\section{Telementoring and clinical case discussion}

Certified health workers were invited to join regular (eg, weekly or monthly) case-based sessions and to present case studies or clinical questions for discussion following a standardised template. Mentors from the hub facilitated the discussion and provided a short didactic presentation on a related topic chosen based on participant needs. Training and mentoring followed Vietnam guidelines and international norms. The didactic portion of the sessions was recorded and made available to participants on request. Additional one-on-one telementoring between the mentor team and a clinic site was held as needed. These sessions included consultation on clinical cases or discussion on clinic quality measurement and improvement projects.

\section{Programme implementation network meetings}

As mentors and participants became more familiar with the technology and the model, the telehealth programme was increasingly used to support implementation of programmatic priorities. For example, the $\mathrm{MOH}$ used the telehealth networks to rapidly disseminate guideline changes and information on medication shortages. An HIV treatment failure programme was established to support the roll-out of HIV viral load testing and to improve the diagnosis and management of first-line treatment failure. Community organisations used a telehealth network to share information about the benefits of viral load testing when the public programme was shifting from CD4 cell to viral load monitoring. Other examples of the use of the telehealth programme to support programmatic priorities are listed in figure 1.

\section{PROGRAMME EVALUATION}

To monitor implementation and track the scale-up of the programme, we routinely collected data from each hub on the number of sessions, number of participating sites per session and number of participants per session. In addition, to assess the effectiveness of the programme and participant satisfaction, we conducted an online survey in April 2018. The questionnaire was in the local language, that is, Vietnamese. The link to the questionnaire was sent to all participants who had provided an active email address. Data were collected through Research Electronic Data Capture electronic data capture tool hosted at the Beth Israel Deaconess Medical Center (BIDMC). ${ }^{24}$ The online form was developed using skip logic and features to prevent incomplete answers and limit erroneous responses. A retrospective pretest-post-test methodology was used to assess the effectiveness of the model. ${ }^{25}$ Participants were asked to rate their own level of competence in different areas of HIV care at the time of the survey and prior to participation in the telehealth programme 
using a 7-point Likert scale: (1) none or no skill at all; (2) vague knowledge, skills or competence; (3) light knowledge, skills or competence; (4) average among my peers; (5) competent; (6) very competent; and (7) expert, teach others. ${ }^{15}$ Participant satisfaction was assessed using a 5-point Likert scale: (1) strongly disagree; (2) disagree; (3) neutral; (4) agree; and (5) strongly agree. To try to maximise the response rate, the survey link was opened for 3 weeks and during that time two reminder emails were sent to those who had not responded yet. We chose 3 weeks based on data from SurveyMonkey showing that $95 \%$ of responses to email survey invitations occur within 3 weeks: $80 \%$ within 7 days, $11 \%$ during the second week and $4 \%$ during the third week. ${ }^{26}$

Data were collected anonymously. The protocol was reviewed in accordance with the US Centers for Disease Control and Prevention (CDC) human research protection procedures and was determined to be non-research (protocol number 2016-285). The data were analysed using Stata V.14.2 (StataCorp, College Station, TX). Descriptive statistics were used to describe the characteristics of the participants including age, gender, education and HIV patient care experience. Likert scale data (satisfaction, competence) were analysed first using frequency distribution, and then combined into two categories of 'agree/strongly agree' versus 'strongly disagree/ disagree/neutral' for satisfaction, and 'competent/very competent/expert, teach others' versus 'none or no skill at all/vague knowledge, skills or competence/light knowledge, skills or competence/average among my peers' for competence. We used the McNemar test to compare the differences between the retrospective pretest and posttest. This work was supported by PEPFAR through the US CDC under the terms of Cooperative Agreement 5U2GGH001140.

\section{RESULTS}

As of December 2018, after 4 years of implementation, 17 institutions and healthcare facilities across Vietnam were implementing HIV telehealth programmes, including 10 from the national or regional level and seven from the provincial level of the healthcare system (table 1). Of the 17 hubs, 12 recorded and reported data on their telehealth activities. Most of the hubs without available data were those that had just initiated the programme and did not put the monitoring system in place or have the manpower for it. During the reporting period, these hubs collectively organised 637 HIV-focused case-based sessions with more than 40000 participant contacts from 694 clinical sites across 62 provinces. Three hubs did not report complete data on number of participants. Of the remaining nine hubs, the average number of participants per session was 43, ranging from 9 to 65 across the hubs. In addition, 1441 health workers from 62 provinces received training certificates through 39 online trainings. Training participants included physicians (60.9\%), nurses $(14.2 \%)$, physician assistants $(13.1 \%)$, midwives $(6.3 \%)$ and other health workers $(5.6 \%)$.

\section{Participant survey}

As of the survey time, a total of 964 email addresses had been used to register to participate in our telehealth activities. The survey was sent out to all of those email addresses $(n=964)$. We assumed that one participant used one email address. A total of 212 programme participants fully completed the survey including self-reported competency and programme satisfaction (response rate $22 \%)$, of which $147(69.3 \%)$ reported having regularly attended a telehealth programme for at least 6 months and $110(51.9 \%)$ reported attending at least one session per month on average over the prior 6 months. The mean age of respondents was $39.3 \pm 9.7$ years and $51 \%$ were female. Respondents came from 44 different provinces, and were physicians $(73.6 \%)$, physician assistants $(10.9 \%)$, nurses $(7.1 \%)$ and other $(8.5 \%)$. They worked at hospitals $(34.9 \%)$, health centres $(33 \%)$, provincial AIDS centres $(25.5 \%)$ and other facility types $(6.6 \%)$. More than half (54.3\%) worked in an HIV outpatient clinic.

\section{Self-reported competence in HIV patient care}

Table 2 shows the change in participants' self-reported level of competence related to HIV clinical management before and after joining the telehealth programme. Participants reported increased knowledge and skills related to HIV care and treatment.

\section{Participant satisfaction}

Participants reported high satisfaction with the programme (figure 3). More than $85 \%$ of respondents agreed that access to the telehealth programme had improved the quality of care they provided to their patients. Eighty-five per cent reported that the sessions were easy to access and the majority reported session technical quality (internet access, sound and picture) as good or very good. Nearly $90 \%$ reported that they would like to continue to participate in future telehealth sessions.

Survey respondents also reported a change in how they access CME following participation in the telehealth programme. The proportion reporting the need to travel outside one's own province for training decreased from $25.5 \%$ to $17.5 \%$ and live online training participation increased from $26.4 \%$ to $40.1 \%$. Live online training became the most common reported way respondents accessed CME. Additionally, 53.8\% reported being willing to pay for CME credits obtained through telehealth.

\section{PROGRAMME SIGNIFICANCE}

Four key issues have been identified as necessary to promote sustainability and country ownership of PEPFAR initiatives: aligning resources with national government health strategies and plans, pursuing a range of financing strategies, establishing evidence-based service delivery models adaptable to advancements in HIV prevention 
Table 1 Established hubs and networks

\begin{tabular}{|c|c|c|c|}
\hline Hub & Location & Catchment area & Programme areas \\
\hline \multicolumn{4}{|c|}{ National and regional levels $(n=10)$} \\
\hline $\begin{array}{l}\text { National Hospital of Tropical } \\
\text { Diseases }\end{array}$ & Hanoi & $\begin{array}{l}\text { Provincial-level HIV clinics in northern } \\
\text { and central Vietnam }\end{array}$ & Adult HIV care and treatment \\
\hline $\begin{array}{l}\text { Vietnam National Children's } \\
\text { Hospital }\end{array}$ & Hanoi & $\begin{array}{l}\text { Provincial-level paediatric HIV clinics in } \\
\text { northern and central Vietnam }\end{array}$ & Paediatric HIV care and treatment \\
\hline $\begin{array}{l}\text { National Hospital of Obstetrics } \\
\text { and Gynecology }\end{array}$ & Hanoi & $\begin{array}{l}\text { Provincial-level antenatal clinics in } \\
\text { northern and central Vietnam }\end{array}$ & PMTCT and reproductive health \\
\hline Hanoi Medical University & Hanoi & $\begin{array}{l}\text { Provincial-level MMT centres in northern } \\
\text { and central Vietnam }\end{array}$ & Addiction and mental health \\
\hline $\begin{array}{l}\text { University of Medicine and } \\
\text { Pharmacy in HCMC }\end{array}$ & HCMC & $\begin{array}{l}\text { Provincial-level hospitals and MMT } \\
\text { clinics in southern and central Vietnam }\end{array}$ & $\begin{array}{l}\text { Addiction and mental health } \\
\text { HIV-hepatitis coinfection }\end{array}$ \\
\hline VNP+ & HCMC & Community & Community advocacy and education \\
\hline Hospital of Tropical Diseases & HCMC & $\begin{array}{l}\text { Provincial-level HIV clinics in southern } \\
\text { and central Vietnam }\end{array}$ & Adult HIV care and treatment \\
\hline Children's Hospital No 1 & HCMC & $\begin{array}{l}\text { Provincial-level paediatric HIV clinics in } \\
\text { southern and central Vietnam }\end{array}$ & Paediatric HIV care and treatment \\
\hline Tu Du Hospital & HCMC & $\begin{array}{l}\text { Provincial-level antenatal clinics in } \\
\text { southern and central Vietnam }\end{array}$ & PMTCT and reproductive health \\
\hline Pasteur Institute & HCMC & $\begin{array}{l}\text { Preventive medicine centres in southern } \\
\text { and central Vietnam }\end{array}$ & Infectious disease emergencies \\
\hline \multicolumn{4}{|l|}{ Provincial level ( $n=7)$} \\
\hline HCMC PAC & HCMC & $\begin{array}{l}\text { District and ward-level HIV clinics in } \\
\text { HCMC and nearby provinces }\end{array}$ & $\begin{array}{l}\text { HIV care and treatment } \\
\text { HIV testing and counselling } \\
\text { Treatment failure and VL testing }\end{array}$ \\
\hline Hanoi PAC & Hanoi & District-level HIV clinics in Hanoi & $\begin{array}{l}\text { HIV care and treatment } \\
\text { Treatment failure and VL testing }\end{array}$ \\
\hline An Giang PAC & An Giang & $\begin{array}{l}\text { District and ward-level HIV clinics in An } \\
\text { Giang }\end{array}$ & $\begin{array}{l}\text { HIV care and treatment } \\
\text { Treatment failure and VL testing } \\
\text { Community health education }\end{array}$ \\
\hline Thai Binh PAC & Thai Binh & District-level HIV clinics in Thai Binh & $\begin{array}{l}\text { Treatment failure and VL testing } \\
\text { Referral system }\end{array}$ \\
\hline Son La PAC & Son La & $\begin{array}{l}\text { District and ward-level HIV clinics in } \\
\text { Son La }\end{array}$ & $\begin{array}{l}\text { HIV care and treatment } \\
\text { Treatment failure and VL testing }\end{array}$ \\
\hline Binh Duong PAC & $\begin{array}{l}\text { Binh } \\
\text { Duong }\end{array}$ & District-level HIV clinics in Binh Duong & $\begin{array}{l}\text { HIV care and treatment } \\
\text { Treatment failure and VL testing }\end{array}$ \\
\hline Ba Ria-Vung Tau PAC & $\begin{array}{l}\text { Ba Ria- } \\
\text { Vung Tau }\end{array}$ & District-level clinics in Ba Ria-Vung Tau & Treatment failure and VL testing \\
\hline
\end{tabular}

HCMC, Ho Chi Minh City; MMT, methadone maintenance therapy; PAC, Provincial AIDS Committee; PMTCT, prevention of mother-to-child transmission; VL, viral load; VNP+, Vietnam Network of People Living with HIV.

and treatment and ensuring adequate models of healthcare provider training and capacity building led by national institutions. ${ }^{10}$ PEPFAR-Vietnam is working with the government of Vietnam to make strides in each of these areas.

Telehealth training and mentoring programmes are increasingly being used in low and middle-income countries (LMIC) to improve access to experts and to decentralise management of complex diseases. ${ }^{27-30}$ Adapting from the Project ECHO experience, we designed, implemented and scaled up a novel HIV telehealth programme for Vietnam, with the goal of building a sustainable training model capable of meeting the country's needs for health worker education, clinical mentoring and programme improvement. The model was rapidly adopted and expanded to provide easy access to HIV providers throughout Vietnam. Both hubs and participants readily embraced the model. Session participation varied depending on the hub and the topic, but participation generally exceeded expectations and, importantly, remained relatively steady over time. In this setting, in March 2019, when ART became eligible for reimbursement by the country's social health insurance system, ${ }^{31}$ telehealth training played an important role in ensuring physicians across the country were certified to prescribe ART under health insurance prior to the programme's 
Table 2 Change in self-reported level of competence related to HIV care and treatment before and after attending the telehealth programme $(n, \%)^{*}$

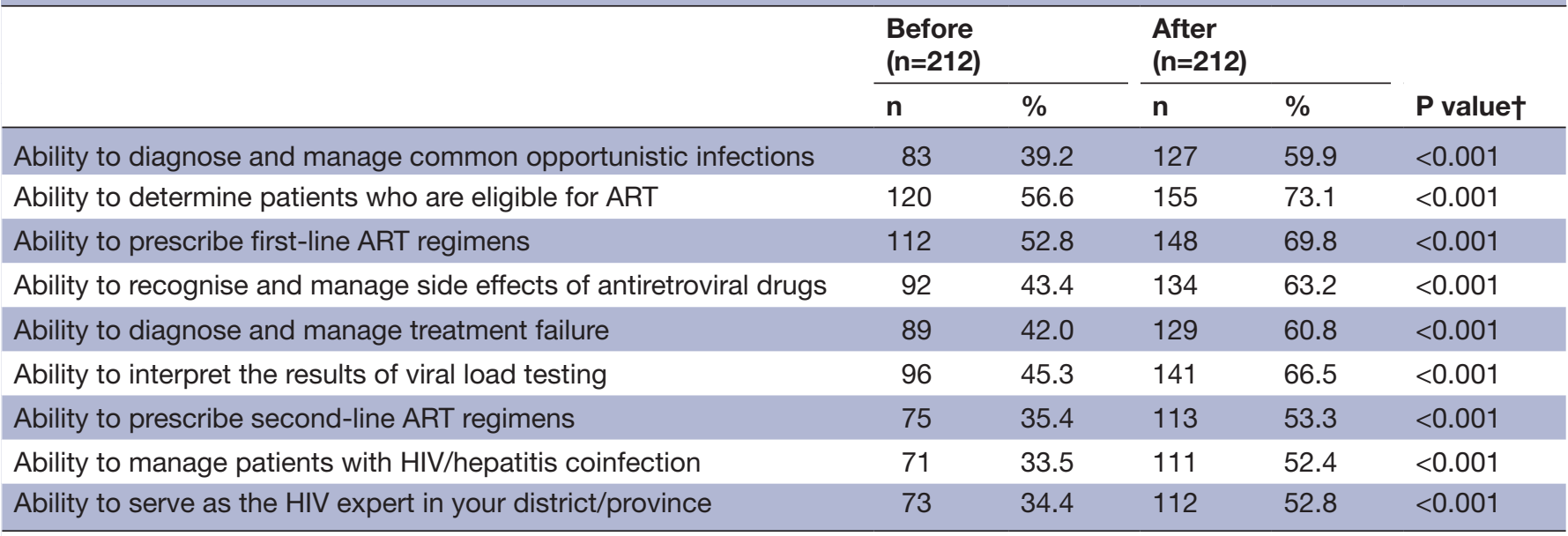

*Number and percentage of respondents who rated themselves 'competent, very competent, or expert, teach other' before and after joining a telehealth programme.

†McNemar test.

ART, antiretroviral therapy.

initiation. As new guidelines and models of care have been introduced (eg, routine HIV viral load testing and pre-exposure prophylaxis), telehealth networks have been central to efforts to disseminate information, train providers and support programme implementation.

While the ECHO model has been used by many training centres, experience in LMICs is still limited. Telehealth has multiple benefits for institutions and participants. It reduces travel and time away from work, improves access to consultation and mentoring from experts, facilitates peer-to-peer learning, ${ }^{32}$ reduces professional isolation ${ }^{33}$ and helps health workers fulfil their CME requirements. ${ }^{19}$ Our experience demonstrates the feasibility, scalability and acceptability of this approach in a resource-limited setting and provides a model for other countries.

There are a number of factors that created favourable conditions for the success of this model in Vietnam. First, Vietnam has an increasingly technology savvy population. As of January 2019, more than $65 \%$ of Vietnam's population have access to the internet, and this rate is much higher among professional workers, including health workers; and the majority of Vietnamese people own a smartphone. ${ }^{34}$ Second, healthcare and information

Participant satisfaction with the HIV Telehealth Programme $\%$ agree or strongly agree $(n=212)$
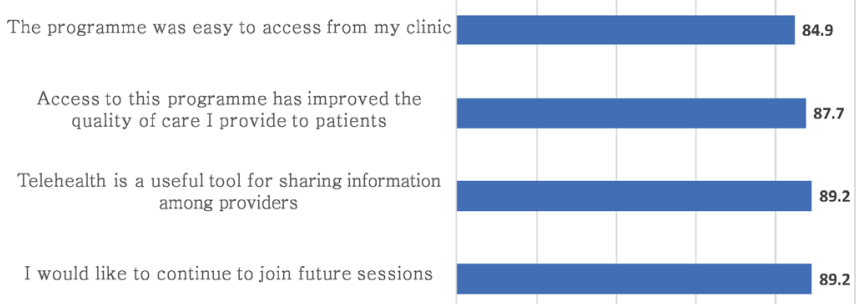

Figure 3 Participant satisfaction with telehealth programme. technology (IT) infrastructure exist throughout the country, including in rural and mountainous regions. As a result, health workers were able access the telehealth programmes from their workplace without the need to travel to specialised e-learning centres. Third, both English language limitations and a strong cultural respect for national and regional health leaders created a strong demand for access to senior in-country experts. Consideration of these factors may be important when considering the adaption and scale-up of telehealth programmes in other settings.

\section{SUSTAINABILITY}

The Vietnam telehealth model was built into and strengthens the country's established system of education and mentoring that relies on national or regional experts to train health workers at the provincial and district levels. Our data suggest that HIV telehealth can also provide benefit to Vietnam's developing CME system. Internetbased CME programmes have been shown to be as effective as traditional formats of CME. ${ }^{19}{ }^{35}$ Since 2016, health workers in Vietnam are required to obtain 24-48 hours of continuing education every 2 years or risk having their practice licence revoked. ${ }^{36}$ This poses a significant challenge for providers working in distant, rural or mountainous regions of the country, as they must travel outside their home province to access quality CME programmes. In our survey, respondents reported a decrease in travel and an increasing use of online training to meet their CME requirement. Additionally, respondents reported a willingness to pay for CME through the telehealth HIV programme. Accrediting telehealth programmes to provide CME is a potential mechanism to ensure financial sustainability of the programme. ${ }^{19}$ 


\section{LESSONS LEARNT AND IMPLEMENTATION CHALLENGES}

Access to high-speed internet for health workers and healthcare facilities is common in Vietnam. As a result, significant potential exists for the health system to use online training and mentoring to build and maintain the health workforce. While there are many forms of online learning, we chose live videoconferencing over traditional forms of e-learning due to the greater flexibility and customisability of the former. We used the cloud-based videoconferencing platform from Zoom, a subscription service requiring an annual fee. Given the rapid pace of technological change, paying for a subscription service provides institutions flexibility compared with investing in development of a customised system. Zoom is userfriendly, and participants unfamiliar with online learning or internet communications joined sessions with minimal support. It is available for desktops and mobile devices and is free for the user, allowing for easy accessibility and scalability.

HIV is a rapidly changing field and training and mentoring must remain adaptable to new local and global recommendations. Start-up costs for software and infrastructure were relatively minor (approximately US\$1000-US\$2000 per hub), allowing for rapid scale-up among training institutions and users. Our 'adapt to adopt' approach facilitated early adoption and, more importantly, fostered innovation. The model was quickly applied to support programme implementation beyond traditional training and clinical mentoring.

While our work focused on building an approach to HIV TA, training institutions in Vietnam have multiple priorities and experts in HIV are also expected to support other infectious disease-related areas. For example, institutions applied the telehealth programme to support capacity building efforts in dengue fever and viral hepatitis. The approach can easily also be adapted for use in non-communicable disease management. In this way, the programme operating costs can be shared and PEPFAR investments in HIV can be leveraged to support the broader health system.

There have been a number of challenges to implementation. First, the IT infrastructure in Vietnam is generally reliable, but the internet signal in remote areas is unstable at times, affecting the quality of the programme. However, only rarely were sessions cancelled or postponed due to internet problems. Second, many health workers had never experienced online or e-learning and were initially unfamiliar with that approach to learning. Some had limited experience with computers and therefore had challenges with installing the Zoom software, accessing the invitation link, or operating the videoconferencing features. Early on this was addressed through on-site IT support by the project team, but ultimately online or telephone support was largely sufficient. Third, some clinic computers lacked webcams and speakers limiting access to the programme. Initially, these items were provided through project support, but once the telehealth programme was more established and trusted, hospitals or health departments provided the necessary equipment. Fourth, although programme operation costs are relatively low, dedicated staff are needed to organise sessions and to coordinate and grow the network. This can be a challenge for some institutions with limited human resources. Fifth, strong facilitation skills are necessary to ensure the quality of sessions. Training of mentors with peer feedback following sessions can improve facilitation of online meetings. Lastly, participants can be reluctant to prepare and present cases for discussion. Programmes must consider how to motivate or incentivise active engagement from participants.

Our programme evaluation had several limitations. About half of participating hubs were able to report all requested data. As a result, our report may underestimate the extent of the programme scale-up. Additionally, only a relatively small percentage of programme participants responded to our participant survey. Response rate is generally lower in online surveys than in in-person surveys. We did not find any previous data indicating what is an adequate response rate. In the review by Nulty, ${ }^{37}$ the response rate of the online surveys ranged from $20 \%$ to $40 \%$. Our response rate was in the low range $(22 \%)$ even though we applied multiple approaches to increase it such as making the questionnaire short, clear and easy to complete; assuring the participants of anonymity of their responses; extending the survey duration up to 3 weeks; involving programme facilitators and sending multiple reminders. It may be due to the fact that we did not provide any incentive to participants for completing the survey. In order to reduce any potential barriers to accessing the telehealth programmes, we did not require participants to register prior to joining (with the exception of certificate training). As a result, we cannot compare the characteristics of survey respondents with non-respondents. Thus, it is possible that the results of self-reported competence and programme satisfaction may not be representative of the overall participant population.

\section{NEXT STEPS}

To ensure the continued relevance of their programme, hubs update their programme schedules on an annual basis. For the upcoming period, telehealth programmes will focus on current priority initiatives of the national HIV programme including scale-up of pre-exposure prophylaxis, transition to new antiretrovirals such as dolutegravir and management of important comorbidities such as hepatitis C. In addition, as HIV prevention and treatment services in Vietnam are increasingly available in private sector clinics, new hubs and programmes will provide training and mentoring to health workers in these settings with a particular focus on pre-exposure prophylaxis and diagnosis and management of sexually transmitted infections.

\section{CONCLUSIONS}

An HIV telehealth programme has been successfully implemented and scaled up nationwide with 
participation of training institutions across Vietnam and health workers from nearly all provinces in the country. After participating in the programme, health workers report high satisfaction with the model and increased competence in various aspects of HIV patient care. Our experience demonstrates that a live videoconferencing telehealth approach can help establish an HIV TA platform led by national institutions. HIV telehealth is a scalable, sustainable and effective approach to building HIV health worker capacity.

\author{
Author affiliations \\ ${ }^{1}$ The Partnership for Health Advancement in Vietnam, Beth Israel Deaconess \\ Medical Center, Hanoi, Vietnam \\ 2Department of Medicine, Beth Israel Deaconess Medical Center, Boston, \\ Massachusetts, USA \\ ${ }^{3}$ The Partnership for Health Advancement in Vietnam, Beth Israel Deaconess \\ Medical Center, Ho Chi Minh City, Vietnam \\ ${ }^{4}$ National Hospital of Tropical Diseases, Hanoi, Vietnam \\ ${ }^{5}$ National Hospital of Obstetrics and Gynaecology, Hanoi, Vietnam \\ ${ }^{6} \mathrm{Hanoi}$ Centre for Disease Control, Hanoi, Vietnam \\ ${ }^{7}$ Son La Provincial AIDS Committee, Son La, Vietnam \\ ${ }^{8}$ Hospital for Tropical Diseases, Ho Chi Minh City, Vietnam \\ ${ }^{9}$ Provincial AIDS Committee of HCMC, Ho Chi Minh City, Vietnam \\ ${ }^{10}$ Department of Infectious Diseases, Pediatric Hospital No 1, Ho Chi Minh City, \\ Vietnam \\ ${ }^{11}$ Tu Du Hospital, Ho Chi Minh City, Vietnam \\ ${ }^{12}$ An Giang Provincial AIDS Committee, Long Xuyen, An Giang, Vietnam \\ ${ }^{13}$ Thai Binh Provincial AIDS Committee, Thai Binh, Vietnam \\ ${ }^{14}$ Vietnam National Hospital of Pediatrics, Hanoi, Vietnam \\ ${ }^{15}$ Centers for Disease Control and Prevention, Ho Chi Minh City, Vietnam \\ ${ }^{16}$ Centers for Disease Control and Prevention, Hanoi, Vietnam
}

Twitter Todd M Pollack @toddmpollack

Contributors TMP, VTTN and LC conceived the idea of the work described here. All authors contributed to the implementation of the work and conduct of the research. LTTT did the data cleaning and DTH did the data analysis. TMP drafted the manuscript. NLC revised the manuscript. All authors provided review and revisions and gave their approval for publication.

Funding This study was funded by the Centers for Disease Control and Prevention (5U2GGH001140).

Competing interests None declared.

Patient consent for publication Not required.

Ethics approval The protocol was approved by the Institutional Review Board of Beth Israel Deaconess Medical Center.

Provenance and peer review Not commissioned; externally peer reviewed.

Data availability statement All data relevant to the study are included in the article .Deidentified survey data will be available from the corresponding author upon reasonable request, and reusing data requires permission from the corresponding author.

Open access This is an open access article distributed in accordance with the Creative Commons Attribution Non Commercial (CC BY-NC 4.0) license, which permits others to distribute, remix, adapt, build upon this work non-commercially, and license their derivative works on different terms, provided the original work is properly cited, appropriate credit is given, any changes made indicated, and the use is non-commercial. See: http://creativecommons.org/licenses/by-nc/4.0/.

ORCID iD

Todd M Pollack http://orcid.org/0000-0002-0011-5233

\section{REFERENCES}

1 Vietnam Administration of HIV/AIDS Control (VAAC). Conference on 20 years of antiretroviral therapy in Vietnam, 2019.
2 UNAIDS. Viet Nam commits to new HIV treatment targets, 2014. Available: http://unaids.org.vn/en/viet-nam-commits-to-new-hivtreatment-targets/ [Accessed 23 Jun 2019].

3 Nguyen DB, Do NT, Shiraishi RW, et al. Outcomes of antiretroviral therapy in Vietnam: results from a national evaluation. PLoS One 2013;8:e55750.

4 Cosimi LA, Dam HV, Nguyen TQ, et al. Integrated clinical and quality improvement coaching in son La Province, Vietnam: a model of building public sector capacity for sustainable HIV care delivery. BMC Health Serv Res 2015;15:269.

5 Williams AB, Le ST, Colby D, et al. Effectiveness of train-the-trainer HIV education: a model from Vietnam. J Assoc Nurses AIDS Care 2014;25:341-50.

6 Jones M, Cameron D. Evaluating 5 years' NIMART mentoring in South Africa's HIV treatment programme: Successes, challenges and future needs. S Afr Med J 2017;107:839-42.

7 Chien E, Phiri K, Schooley A, et al. Successes and challenges of HIV mentoring in Malawi: the Mentee perspective. PLoS One 2016;11:e0158258-14.

8 World Health Organization. Who recommendations for clinical mentoring to support scale-up of HIV care, antiretroviral therapy and prevention in resource-constrained settings, 2006. Available: https://www.who.int/hiv/pub/guidelines/clinicalmentoring.pdf? ua $=1$

9 Vietnam Administration of HIV/AIDS Control (VAAC). Optimizing Viet Nam 'S HIV response: an investment case, 2014. Available: https://www.aidsdatahub.org/sites/default/files/publication/Vietnam investment_case_2014.pdf

10 Palen J, El-Sadr W, Phoya A, et al. PEPFAR, health system strengthening, and promoting sustainability and country ownership. $J$ Acquir Immune Defic Syndr 2012;60:S113-9.

11 Young JD, Abdel-Massih R, Herchline T, et al. Infectious diseases Society of America position statement on telehealth and telemedicine as applied to the practice of infectious diseases. Clin Infect Dis 2019;68:1437-43.

12 Kiviat AD, Geary MC, Sunpath $\mathrm{H}$, et al. Hiv online provider education (hope): the Internet as a tool for training in HIV medicine. J Infect Dis 2007;196:S512-5.

13 Wood BR, Unruh KT, Martinez-Paz N, et al. Impact of a telehealth program that delivers remote consultation and longitudinal mentorship to community HIV providers. Open Forum Infect Dis 2016;3:1-9.

14 Leone M, Corsi FM, Ferrari F, et al. Teleneurology in sub-Saharan Africa: experience from a long lasting HIV/AIDS health program (DREAM). J Neurol Sci 2018;391:109-11.

15 Arora S, Kalishman S, Thornton K, et al. Expanding access to hepatitis $\mathrm{C}$ virus treatment--Extension for Community Healthcare Outcomes $(\mathrm{ECHO})$ project: disruptive innovation in specialty care. Hepatology 2010;52:1124-33.

16 Arora S, Thornton K, Murata G, et al. Outcomes of hepatitis C treatment by primary care providers. N Engl J Med 2011;364:1-12.

17 Parsons EC, Mattox EA, Beste LA, et al. Development of a sleep telementorship program for rural department of Veterans Affairs primary care providers: sleep Veterans Affairs extension for community healthcare outcomes. Ann Am Thorac Soc 2017;14:267-74.

18 Marciano S, Haddad L, Plazzotta F, et al. Implementation of the $\mathrm{ECHO}^{\circledast}$ telementoring model for the treatment of patients with hepatitis C. J Med Virol 2017;89:660-4.

19 Arora S, Kalishman SG, Thornton KA, et al. Project echo: a Telementoring network model for continuing professional development. J Contin Educ Health Prof 2017;37:239-44.

20 Zurawski A, Komaromy M, Ceballos V, et al. Project echo brings innovation to community health worker training and support. $J$ Health Care Poor Underserved 2016;27:53-61.

21 Katzman JG, Comerci G, Boyle JF, et al. Innovative telementoring for pain management: project echo pain. J Contin Educ Health Prof 2014;34:68-75

22 Lewiecki EM, Bouchonville MF, Chafey DH, et al. Bone health echo: telementoring to improve osteoporosis care. Womens Health 2016;12:79-81.

23 Vermeil T, Peters A, Kilpatrick C, et al. Hand hygiene in hospitals: anatomy of a revolution. $J$ Hosp Infect 2019;101:383-92.

24 Harris PA, Taylor R, Thielke R, et al. Research electronic data capture (REDCap)--a metadata-driven methodology and workflow process for providing translational research informatics support. J Biomed Inform 2009;42:377-81.

25 Thomas EV, Wells R, Baumann SD, et al. Comparing traditional versus retrospective Pre-/Post-assessment in an interdisciplinary leadership training program. Matern Child Health J 2019;23:191-200. 
26 Zheng J. How many days does it take for respondents to respond to your survey? Available: https://www.surveymonkey.com/curiosity/ time-to-respond/ [Accessed 3 Mar 2020].

27 Nartker AJ, Stevens L, Shumays A, et al. Increasing health worker capacity through distance learning: a comprehensive review of programmes in Tanzania. Hum Resour Health 2010;8:1-10.

28 Reid MJA. Flam R, Tsiouris $f$. new models for medical education: web-based Conferencing to support HIV training in sub-Saharan Africa. Telemed e-Health.

29 Randriambelonoro M, Bagayoko C-O, Geissbuhler A. Telemedicine as a tool for digital medical education: a 15-year journey inside the raft network. Ann N Y Acad Sci 2018;1434:333-41.

30 Chang LW, Kadam DB, Sangle S, et al. Evaluation of a multimodal, distance learning HIV management course for clinical care providers in India. J Int Assoc Physicians AIDS Care 2012;11:277-82.

31 USAID. U.S. and Vietnam celebrate first patients receiving antiretrovirals covered by social health insurance, 2019. Available: https://vn.usembassy.gov/20190308 first-patients-receiving- antiretrovirals-covered-by-social-health-insurance/ [Accessed 23 Jun 2019].

32 Keynejad R, Ali FR, Finlayson AET, et al. Telemedicine for peer-topeer psychiatry learning between U.K. and Somaliland medical students. Acad Psychiatry 2013;37:182.

33 Lewis H, Becevic M, Myers D, et al. Dermatology ECHO - an innovative solution to address limited access to dermatology expertise. Rural Remote Health 2018;18:4415.

34 VNETWORK. Vietnam Internet statistics, 2019. Available: https:// vnetwork.vn/en/news/cac-so-lieu-thong-ke-internet-viet-nam-2019 [Accessed 3 Mar 2020].

35 Wutoh R, Boren SA, Balas EA. eLearning: a review of Internetbased continuing medical education. J Contin Educ Health Prof 2004;24:20-30.

36 Ministry of Health of Vietnam. Guidance on continous training in the health sector. circular No. 22/2013/TT-BYT, 2013.

37 Nulty DD. The adequacy of response rates to online and paper surveys: what can be done? Assess Eval High Educ 2008. 